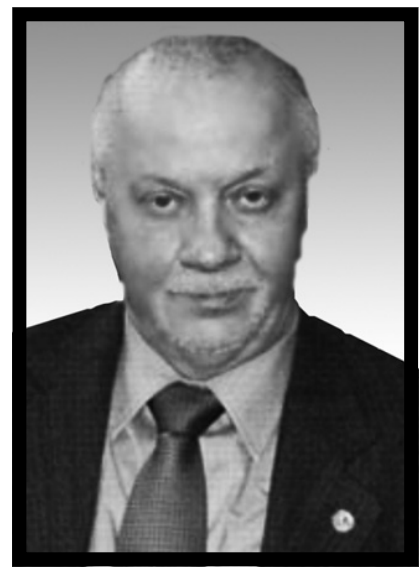

\title{
To the memory of Vladimir Mikhailovich Novotortsev (1946-2018)
}

Vladimir Mikhailovich Novotortsev, Academician of the Russian Academy of Sciences, Professor, Doctor of Chemical Sciences, a prominent specialist in magnetically active substances and materials, who worked at the Academy of Sciences for more than 40 years, passed away on August 23, 2018.

V. M. Novotortsev was born on March 30, 1946, in the Platnirovskaya village of the Krasnodar Territory. In 1970, he graduated from the Faculty of Molecular and Chemical Physics of the Moscow Institute of Physics and Technology (MIPT) and was admitted to the MIPT post-graduate courses. In 1974 he defended PhD Thesis entitled "Magnetic properties of transition metal exchange clusters". After that, the whole V. M. Novotortsev's academic career was tightly connected with the N. S. Kurnakov Institute of General and Inorganic Chemistry, Russian Academy of Sciences (IGIC RAS), where he worked his way up from an assistant researcher to a Doctor of Chemical Sciences (1989), a Corresponding Member (2000) and Full Member of the RAS (2008). From 2005 to 2015 inclusive, Vladimir Mikhailovich headed the IGIC RAS. Till the end of his life, he headed the Laboratory of Magnetic Materials and was the Research Supervisor of the Institute.

V. M. Novotortsev's works largely stimulated the development of the chemistry of magnetic semiconductors in Russia. He supervised the development of targeted syntheses of polynuclear transition metal clusters, which shed light on the key correlations for targeted modification of the properties of new generation functional materials such as molecular magnets. His scientific achievement provided the basis for the design of innovative magnetic optical devices and for development of original methods for studying the electronic structures of compounds and modeling of the mechanisms of formation of properties with changes in the composition and structure.

The studies headed by Vladimir Mikhailovich included the first analysis of non-Heisenberg magnetic exchange interactions at the molecular level. It was shown that the antisymmetric exchange induces weak ferromagnetism and anisotropic exchange determines important characteristics of molecular magnets such as the direction and rate of relaxation of the magnetization vector. V. M. Novotortsev's contribution to the studies of magnetic interactions cannot be overestimated. The approaches he proposed made it possible to calculate a set of micro and macro parameters determining the behavior of magnetically active compounds, understand the nature of exchange interactions, and interpret the magnetic, magnetooptical, and electrical properties for not only model systems, but also practically important solid-phase materials.

V. M. Novotortsev's scientific achievements described in more than 400 papers and reviews are well-known to Russian and foreign scientists. Special mention should be made of the educational activity of V. M. Novotortsev. His enthusiasm, competence, broad-based knowledge, and the ability to clearly state various aspects of the modern materials science and the chemistry of magnetic materials attracted talented students. Vladimir Mikhailovich supervised more than 20 PhDs and Doctoral Theses.

An important aspect of V. M. Novotortsev's activity belonged to the science organization work. He was Deputy Secretary Academician and Head of the Materials Science Section of the Division of Chemistry and Materials Science of the RAS; he actively participated in the expert work, in particular, for many years he headed the Expert Board in Inorganic Chemistry of the State Commission for Academic Degrees and Titles of the RF Ministry of Education and Science. His many-year work as Deputy Editor-in-Chief of Russian Journal of Inorganic Chemistry and a member of Editorial Boards of the Russian Journal of Coordination Chemistry and Russian Chemical Bulletin deserves special mention.

The successful and many-sided activity of Academician V. M. Novotortsev was awarded by the State Prize of the Russian Federation, RF Friendship Order, RF Order of Honor, the N. S. Kurnakov Gold Medal of the Russian Academy of Sciences, and Prizes of the Russian Academy of Sciences.

Vladimir Mikhailovich was a kind, sympathetic, and decent person and a faithful and reliable friend. His great contribution to Russian science will never be forgotten. The cherished memory of Vladimir Mikhailovich Novotortsev will remain in the hearts of his colleagues and students.

Published in Russian in Izvestiya Akademii Nauk. Seriya Khimicheskaya, No. 10, p. 1942, October, 2018.

1066-5285/18/6710-1942 (c) 2018 Springer Science+Business Media, Inc. 